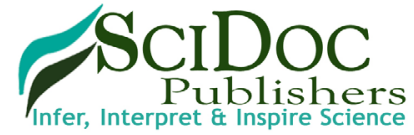

\section{Prevalence of Ovine Lungworm and Associated Risk Factors in and Around Debre Berhan Town, Ethiopia}

\section{International Journal of Veterinary Health Science \& Research (IJVHSR)}

ISSN 2332-2748

Bekele T, Shibbiru T*

School of Veterinary Medicine, Wolaita Sodo University, Ethiopia.

\title{
Abstract
}

A cross sectional study was conducted in and around Debre Berhan town, Ethiopia from November 2016 to April 2017. The objectives of study were to estimate the prevalence of lungworm infection and associated risk factors in sheep. Coproscopic examination was done by using a modified Baermann technique. Fecal samples were collected from randomly selected sheep of systematically chosen households. The study animals were composed of different breeds, age groups, sexes, management systems, and subjected to different health care conditions. Out of 378 sheep examined, 69 (18.3\%) were found to be positive for one or more species of lungworm parasites. Dictyocaulus filaria $(6.6 \%)$ was the predominant species of parasite identified followed by Muellerius capillaries (5.6\%) Protostrongylus rufescens $(2.6 \%)$ and mixed infection of D. filaria and $M$. capillaries $(3.5 \%)$. There was statistically significant difference in prevalence of lungworm parasite $(\mathrm{P}<0.05)$ among the risk factors like respiratory signs, deworming history, and management systems. Animals with respiratory signs, not dewormed, and managed under extensive production system were more infected with the parasites. On the other hand, the prevalence of the parasites among breeds, age groups, and sexes showed no statistically significant difference $(\mathrm{P}>0.05)$. Despite the smaller prevalence observed in this study, ovine lungworm is still a constraint to sheep in the area in different season of the year, and therefore, vigorous controlling strategy should be implemented to reduce the prevalence of infection.

Keywords: Debre Berhan; Lungworm; Prevalence; Risk Factors and Sheep.

\section{Introduction}

Among African countries, Ethiopia is known by having the highest number of livestock population. Sheep are among the most important livestock species kept by highlanders' in the country; used for meat production and immediate cash income next to poultry. However, about half of all sheep mortality and morbidity on farms in Ethiopian highlands are caused by pneumonia and endo-parasitism including lungworms $[5,21]$. Lungworm is the common parasitic disease of sheep in the country because of it is ubiquitous and prevalent within many tropical and subtropical environments that provide nearly perfect conditions for survival and development of their larval stage. The parasites are round worms (nematodes) belonging to the phylum Nemathelminthes and grouped under Metastrongyloidea or Trichostrongyloidea super families [34].

Prevalence of small ruminant lungworm is different based on geographical and climatic factors of spatial area. It is host specific and common in areas of mild high rain fall and abundant grass [27]. The prevalence of infection is low in spring and summer and rises rapidly in the autumn and winter $[9,34]$.

The pathogenesis of lungworms depends on their location within the respiratory tract, the number of infective larvae ingested, the animal immune state, and the nutritional status and age of the host $[27,34]$. Severe infection with lungworm can cause vasculitis and perivasculitis with infiltration of inflammatory cells in and around the vascular wall and thickening of interalveolar walls and mononuclear cell infiltration due to inflammatory response in lung, the resulting effect is known as verminous pneumonia [14].

Debre Berhan and the surrounding areas are the central high land part of Ethiopia and local sheep breed of the place is known as Menz breed; they are high wool producers. Farmers in the area have experienced and getting benefit from wool production; consequently, sheep remain a source of wool for the last fifty years to Debre Berhan textile factory. Wool production as source of

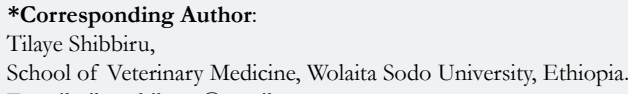

Citation: Bekele T, Shibbiru T (2017) Prevalence of Ovine Lungworm and Associated Risk Factors in and Around Debre Berhan Town, Ethiopia. Int J Vet Health Sci Res. 5(6), 190-195. doi: http://dx.doi.org/10.19070/2332-2748-1700038

Copyright: Shibbiru T ${ }^{\circ}$ 2017. This is an open-access article distributed under the terms of the Creative Commons Attribution License, which permits unrestricted use, distri bution and reproduction in any medium, provided the original author and source are credited. 
income has immense contribution in livelihood of the community. Considering their economic value government and breeders have attempted to improve the existing local breed using Awassi and Dorper exotic sheep breed. However, various challenging factors including infectious diseases have severely hampered productivity. Among the diseases incriminated lungworm infection is known to affect wool production through unthriftiness and loss of weight [32]. Inspite of its importance, there is little documentation and consideration of the case in and around Debre Berhan town. Therefore, the objectives of study were to estimate the prevalence of lungworm infection through Coproscopic examination and associated risk factors in sheep in area.

\section{Materials And Methods}

\section{Study Area}

The study was conducted in and around Debre Berhan town, 130 km North-East of Addis Ababa from November 2016 to April 2017. Debre Berhan is located at an altitude of 2800 m.a.s.l. The area has a bimodal rain fall consisting of long (June to September) and short (March to April) rainy season. The average annual rain fall and temperature are $1728 \mathrm{~mm}$ and $15.84^{\circ} \mathrm{C}$, respectively. Livestock population comprises of 144,638 bovine, 97,815 sheep, and 47,970 goats, 39,038 equine and 96,821 poultry (CSA, 2010).

\section{Study Animals}

The study animals were 378 sheep of different breeds, age group, sexes, and managed under different production systems. Breeds of sheep comprised (251) local (Menz), (39) exotic (Dorper) and (88) cross breeds of Awassi and Dorper with local once. Both sexes were included in the study; 158 were male and 220 were female sheep. The animals were kept under either extensive or semi-intensive management system. The age of animals was categorized into young and adult based on the guidelines forwarded by Aillo and Mays (1998) [4]. Based on their body condition score, animals were classified as poor, medium and good as outlined in ESGPIP (2007) [16]. The respiratory signs observed and deworming history of each examined sheep were also recorded.

\section{Sampling Techniques and Sample Size Determination}

Of nine kebeles found in and around Debre Berhan town, three kebeles were selected by lottery system. From these kebeles, households were selected systematically with an interval of four houses. Sheep from each selected household were examined with a proportion of each household's stock size by random selection from the herd. The desired sample size for the study was calculated by using the formula given by Thrusfield (2007) [36]. The previous prevalence report of lungworm infection in sheep in Debre Berhan town was reported to be 56.3\% [32]. Therefore, an expected prevalence of $56.3 \%$ will be taken to estimate the sample size. Taking 95\% confidence level, and 5\% precision. A total of 378 sheep were needed to establish the prevalence.

\section{Sample Collection and Coproscopic Examination}

Fecal samples were collected from each sheep per rectum by using glove and universal bottles, and freshly transported to Veterinary
Laboratory of Debre Berhan Agricultural Research Center. All samples were labeled with; date of collection, site, breed, sex, age, deworming history, and respiratory signs of animals by using permanent marker.

In the laboratory, fresh faeces were subjected to coprological examination for the detection of L1 larvae using modified Baermann techniques [11,34]. Accordingly, about 10-15 grams of faeces were weighed and then, enclosed in double layered gauze, suspended and fixed in a beaker containing hot water (up to $18^{\circ} \mathrm{C}$ ) by using a string rod. The whole apparatus was stayed for about twenty four hours, and then the sediment was examined under low power magnification (10x). When positive, a drop of $1 \%$ iodine solution was used to immobilize the larvae and use (40x) magnification power for identification of species of the parasites. Larvae were identified based on morphological characteristics. For D. filaria, L1 has a characteristic cuticular knob at the anterior extremity and bluntly pointed tail and dark to brownish granulation of the intestinal cells. The other ovine lungworms are devoid of anterior protoplasmic knob. P. rufescens has a wavy outline at the top of its tail but without dorsal spine and $M$. capillaries have an undulating tip and a dorsal spine [15].

\section{Data Analysis}

The results of fecal examination were entered into Microsoft Excel spread sheet (Microsoft ${ }^{\circledR}$ office excel 2007) and SPSS version 20 for two way analysis. Descriptive analysis was used to describe the result of proportion analysis. Prevalence was estimated as the number of samples detected positive to lungworm from the total sample analyzed. Chi-square was done to study association between lungworm infection and risk factors (breed, age, sex, management system, and deworming history of animals). The significance level was set at 0.05 .

\section{Results}

An overall prevalence of lungworm in this study was estimated to be $18.3 \%$, of which $6.6 \%$ were young and $11.6 \%$ were adult. The prevalence rate of major parasitic species; D. filaria, $M$. capillaries, $P$. rufescens and mixed infection with $D$. filaria and $M$. capillaries were $(6.6 \%),(5.6 \%) .(2.6 \%)$ and $(3.4 \%)$ respectively Table (1).

Out of 378 sheep examined for lungworm, 6.6\% (25/378) young and $11.6 \%(44 / 378)$ adult were found positive. The prevalence of the parasite in female and male animals was estimated to be $11.5 \%$ and $6.9 \%$, respectively. Higher prevalence of $10.6 \%$ (40/378) was seen in Menz breed followed by Awassi $\times$ menz 4.5\% (17/378), Dorper $\times$ menz 1.9\% (7/378), and Dorper $1.3 \%$ $(5 / 378)$ breeds. There was no statistically significant difference among breeds $\left(\chi^{2}=0.948 ; \mathrm{P}=0.33\right)$ in harboring the parasite. Based on body conditions, a prevalence of $10.8 \%, 6.1 \%, 1.3 \%$, was found in animals with poor, medium, and good body condition, respectively. Animals with poor body condition were significantly affected with lungworm $\left(\chi^{2}=8.658 ; \mathrm{P}=0.003\right)$.

Based on the management system practiced, a prevalence of $15.3 \%$ in extensively managed and $2.9 \%$ semi-intensively managed animals were found positive. There was statistically significant difference $\left(\chi^{2}=6.354 ; \mathrm{P}=0.012\right)$ in prevalence of lungworm between the management systems. The prevalence 
of $7.1 \%$ and $11.1 \%$ was seen in dewormed and non-dewormed animals, respectively. The infection rate was statistically significant $\left(\chi^{2}=43.27 ; \mathrm{P}=0.000\right)$ in non-dewormed animals (Table 2).

Of the total sheep examined; 270 were apparently healthy and 108 sheep presented with respiratory signs (like coughing and nasal discharge). A prevalence of $4.8 \%$, and $13.5 \%$ was seen in animals that were apparently healthy, and respiratory signs, respectively.
There was statistically significant difference $\left(\chi^{2}=58.249 ; \mathrm{P}=0.000\right)$ in lungworm infection between sheep with presentation of respiratory signs and apparently healthy sheep (Table 2).

\section{Discussion}

An overall prevalence of lungworm infection in the study animals of the area was $18.3 \%$. This is comparable with the findings of

Table 1. Prevalence of Lungworm in a Total of 378 Examined Sheep in and Around Debre Berhan Town Based on Species of the Parasites.

\begin{tabular}{|c|c|c|}
\hline Species of Worms & Number of Positive Animals & Prevalence (\%) \\
\hline D. filarial & 25 & 6.6 \\
\hline M. capillaries & 21 & 5.6 \\
\hline P. rufescens & 10 & 2.6 \\
\hline Mixed infection & 13 & 3.4 \\
\hline Total & 69 & 18.3 \\
\hline
\end{tabular}

Table 2. Prevalence of Ovine Lungworm in and Around Debre Brehan Town with Related Risk Factors from 2016 to 2017.

\begin{tabular}{|c|c|c|c|c|c|c|c|c|}
\hline \multirow[b]{2}{*}{ Risk factors } & \multirow{2}{*}{$\begin{array}{c}\text { Animals } \\
\text { examined } \\
(\%)\end{array}$} & \multicolumn{7}{|c|}{ Prevalence of lungworm species (\%) } \\
\hline & & D. filaria & M. capillaries & P. rufescens & Mixed infection & $\begin{array}{c}\text { Total } \\
\text { positive }(\%)\end{array}$ & $\mathbf{X}^{2}$ & P-value \\
\hline \multicolumn{9}{|c|}{ Adress } \\
\hline Kebele 04 & $108(28.6)$ & $9(2.4)$ & $5(1.3)$ & $3(0.8)$ & $2(0.5)$ & $19(5)$ & \multirow{3}{*}{0.13} & \multirow{3}{*}{0.715} \\
\hline Kebele 07 & $128(33.9)$ & $7(1.9)$ & $9(2.4)$ & $5(1.3)$ & $5(1.3)$ & $26(6.9)$ & & \\
\hline Kebele 09 & $142(37.6)$ & $9(2.4)$ & $7(1.9)$ & $2(0.5)$ & $6(1.6)$ & $24(6.3)$ & & \\
\hline \multicolumn{9}{|c|}{ Breed } \\
\hline Menz & $251(66.4)$ & $10(2.6)$ & $14(3.7)$ & $8(2.1)$ & $8(2.1)$ & $40(10.6)$ & \multirow{4}{*}{0.95} & \multirow{4}{*}{0.330} \\
\hline Dorper & $39(10.3)$ & $1(0.3)$ & $2(0.5)$ & $0(0)$ & $2(0.5)$ & $5(1.3)$ & & \\
\hline Dorper $\times$ Menz & $41(10.8)$ & $2(0.5)$ & $3(0.8)$ & $0(0)$ & $2(0.5)$ & $7(1.9)$ & & \\
\hline Awassi $\times$ Menz & $47(12.4)$ & $12(3.2)$ & $2(0.5)$ & $2(0.5)$ & $1(0.3)$ & $17(4.5)$ & & \\
\hline \multicolumn{9}{|c|}{ Age } \\
\hline Young & $131(34.7)$ & $9(2.4)$ & $9(2.4)$ & $2(0.5)$ & $5(1.3)$ & $25(6.6)$ & \multirow{2}{*}{0.02} & \multirow{2}{*}{0.878} \\
\hline Adult & $247(65.3)$ & $16(4.2)$ & $12(3.2)$ & $8(2.1)$ & $8(3.2)$ & $44(11.6)$ & & \\
\hline \multicolumn{9}{|c|}{ Sex } \\
\hline Female & $220(58.2)$ & $17(4.5)$ & $12(3.2)$ & $7(1.9)$ & $7(1.9)$ & $43(11.4)$ & & \\
\hline Male & $158(41.8)$ & $8(2.1)$ & $9(2.4)$ & $3(1.9)$ & $6(1.6)$ & $26(6.9)$ & 0.13 & 0.722 \\
\hline \multicolumn{9}{|c|}{ Body Condition } \\
\hline Poor & $146(38.6)$ & $18(4.8)$ & $10(2.6)$ & $6(1.6)$ & $7(1.9)$ & $41(10.8)$ & & \\
\hline Medium & $174(46)$ & $6(1.6)$ & $8(2.1)$ & $4(1.1)$ & $5(1.3)$ & $23(6.1)$ & 8.65 & 0.003 \\
\hline Good & $58(15.3)$ & $1(0.3)$ & $3(0.8)$ & $0(0)$ & $1(0.3)$ & $5(2.1)$ & & \\
\hline \multicolumn{9}{|c|}{ Management System } \\
\hline Extensive & $262(69.3)$ & $21(5.6)$ & $18(4.8)$ & $8(2.1)$ & $11(4.2)$ & $58(15.3)$ & 35 & 0012 \\
\hline Semi-intensive & $116(30.7)$ & $4(1.1)$ & $3(0.8)$ & $2(0.5)$ & $2(0.5)$ & $11(2.9)$ & 0.35 & 0.012 \\
\hline \multicolumn{9}{|c|}{ Deworming History } \\
\hline Non-dewormed & $106(28)$ & $14(3.7)$ & $10(2.6)$ & $9(2.4)$ & $9(2.4)$ & $42(11.1)$ & 1227 & 0000 \\
\hline Dewormed & $272(72)$ & $11(2.9)$ & $11(2.9)$ & $1(0.3)$ & $4(1.1)$ & $27(7.1)$ & 43.27 & 0.000 \\
\hline \multicolumn{9}{|c|}{ Respiratory Sign } \\
\hline $\mathrm{No}$ & $270(71.4)$ & $5(1.3)$ & $7(1.9)$ & $1(0.3)$ & $5(1.3)$ & $18(4.8)$ & & \\
\hline Yes & $108(28.6)$ & $20(5.3)$ & $14(3.7)$ & $9(2.4)$ & $8(2.1)$ & $51(13.5)$ & 58.25 & 0.000 \\
\hline Total & $378(100)$ & $25(6.6)$ & $21(5.6)$ & $10(2.6)$ & $13(3.5)$ & $69(18.3)$ & & \\
\hline
\end{tabular}


a prevalence of $13.4 \%$ in Mekelle city [20],17 .5\% around Bahir Dar city [39], 13.1\% in and Around Wukro, Eastern Tigray [30], and $25.24 \%$ in and Around Jimma town.by [18]. However, less prevalence of lungworm infection was obtained in this study when compared with the previous researcher's reports; Tefera and Mekuria (2016) [32] who reported aprevalence of 56.3\% in Debre Birehan town, Regassa et al., (2010) [28] reported a prevalence of $40.4 \%$ in Dessie and Kombolcha districts, Northern Ethiopia, Eyob, Matios (2012) [17] in Assella Central Ethiopia reported a prevalence of $72.44 \%$ and Abebe et al., (2014) [2] reported a prevalence of $58 \%$ in and around Assela, Arsi zone, Ethiopia.

The possible explanation for variation in prevalence of ovine lungworm infection might be due to the differences in agroecology (altitude, rainfall, humidity and temperature difference) of the study areas which is comfortable or not for the survival of parasites larvae, season, management practices and/or it might be due to the nutritional status of the animals which can affect the level of immunity of animals being affected by lungworm $[10,27]$. Moreover, the expansion of animal health extension and veterinary services could also be the probable reason for the variation, the lower prevalence observed in this study may be attributed to increasing farmers' awareness to deworm their animals against parasitic infections.

From the total prevalence (18.3\%) of lungworm infection, D.flaria (Dictyocaulus filaria) was the predominant species in the study area (6.6\%) followed by M.capilaries (Muellerius cappillaris, 5.6\%) and P.rufescens (Protostronglus rufescens, $2.6 \%$ ), which is the least prevalent species. This finding is in line with the previous study by Ibrahim and Godefa, (2012) [20] with a prevalence of 5.9\%, 3.5\%, 2.74\%. But, the researchers like Basaznew et al., (2012) [7], Alemu et al., (2006) [5], and Regassa et al., (2010) [28] showed that M. capillaris was the predominant species involved in the infection rather than D.filaria. Mixed infection with D. filaria and M. capilaries was observed in the current study as in previous studies $[1,17]$.

The reason for the difference in contribution of each parasitic species to the overall prevalence might be attributed to the difference in their life cycles of the parasites. Thus, D. filaria has a direct life cycle and requires shorter time to develop to an infective stage. After ingestion, the larvae of these parasites can be shed with feces within 5 weeks [31]. Unlike to D. filaria, the transmission of $P$. rufescens and $M$. capillaris is epidemiologically complex event involving host, parasite and intermediate host. Because, $P$. refescens has indirect life cycle that requires longer time and wet or rainy warmer season to complete their complex life cycle in the presence of suitable intermediate hosts that create favorable condition for sporadic distribution [27].

The current findings showed that $11.4 \%$ females and $6.9 \%$ males were affected by lungworms. However, there was no statistically significant difference in lungworm infection between sexes. This result was in line with the reports by Beyene et al., (2012) [8] in Ambo District (39.37\% in females, and 28.83\% in males), Eyob and Matios (2013) [7] in Asella province (72.8\% in females and $72.2 \%$ in males), and Gebreyohannes et al., (2013) in Mekedella district $(32.3 \%$ in females and $23.8 \%$ in males), Ethiopia. However, this result contradicted with the findings of Moges et al., (2011) [26] in Wogera District, and Weldesenebet and Mohamed (2012) [38] in Jimma, who reported higher prevalence of lungworm infection in male than female animals. Ibrahim and Godefa
(2012) [20] in Mekelle city and Mihreteab and Aman (2011) [25] in Tiyo District reported higher prevalence of ovine lungworm infection in females than males. The higher infection rate with lungworm in females could be associated with their physiology of reproduction and difference in management [12]. The variations may also be due to the improper distribution of sample selection between the two sexes [3].

About 6.6\% (25/378) of young animals and 11.6\% (44/378) were infected with lung parasites. There was no a statistically significant variation between young and adult sheep. This finding agrees with Mesfin (2008) [24] who reported insignificant difference between age groups. However, Alemu et al., (2006)[5], Mihreteab and Aman (2011) [25] and Abdella et al., (2016) [1] reported that young sheep were significantly affectedby lungworms $(p<0.05)$ than adult sheep. This has been partly explained by the acquired immunity developed in adult and older animals due to previous exposure and sheep that recovered from the infection have better immunity against re-infection $[12,31]$. In contrary to this study Basaznew et al., (2012)[12] reported that the highest prevalence of infections in adult than young sheep.

An attempt was furthermore made to know the influence of breeds of sheep on the overall prevalence of lungworm infection and there is no statistically significant difference $(\mathrm{P}>0.05)$ in the infestation rate among breed types as with the previous study by Tefera and Mekuria (2016))[32] in Debre Berhan town, between local and cross breeds in general. However, a high level of lungworm infection was recorded specifically in Awassi and Menz cross breeds in this study. This might be due to the difference in relative adaptability competence in the area and genetic make-up and pedigrees of animals.

Regarding to the physical body conditions, the prevalence was significantly higher $(\mathrm{P}<0.05)$ in those sheep with poor body conditions than those with medium or good body conditions. The current finding has an agreement with studies reported by Thomson and Orita (2008) [35], Kebede et al., (2014) [22] and Selam et al., (2015) [30], but it disagrees with the finding of Weldesenebet and Mohamed (2012) [38] who reported higher prevalence rate in animals with good body condition. The variation in prevalence among the different body conditions might be associated with immunosuppression in sheep with poor body conditions and concurrent infections by other parasites including gastrointestinal tract helminthes and/or malnutrition [25]. Moreover, it might be due to the fact that poorly nourished animals appear to be less competent in getting ride-off lungworm infection [14].

The level of prevalence was compared between animals kept under extensive and semi-intensive management systems; greater prevalence rate of lungworm infections was observed in animals under extensive management system, than those kept in semi intensive management system. It has a significant difference $(\mathrm{P}<0.05)$ and coincides with the previous results of the study by Yitagel et al., (2013) in North Gondar Zone, Eyob and Matios (2013) [17] in Assella province and Yimer and Desie (2016) [40] in Northern Ethiopia. This could be due to the fact that sheep in extensive management system have a chance of grazing in the field contaminated with intermediate host for P. rufescens and $M$. capillaries or they possibly infested with larvae as well as easily obtained $D$. filarial from the herbage [27]. Another possible 
explanation for the massive infection of sheep in extensive production system is that they were not supplied with appropriate nourishment which provides high computation, getting wide of lungworm infection [23]. However, it contradicted with the result of Weldesenebet and Mohamed(2012) [38] who reported higher prevalence of lungworm infection in sheep under semi-intensive management system than in extensive management system.

On the other hand there was higher statistically significant variation $(\mathrm{P}<0.001)$ in prevalence rate between apparently healthy and those with respiratory signs which had higher level of lungworm infections. This result coincides with the observations reported by Alemuet al (2006)(5), Beyene et al., (2012) [8], Eyob and Matios(2013) [17] and Hasen et al., (2013) [19] in different parts of the country. This might probably due to the fact that during the end of prepatent phase there is development of bronchitis, which is responsible for clinical respiratory signs, developed and caused by immature lungworms in the air ways and cellular infiltration of the epithelium. In about $25 \%$ of heavily infected and then recovered animals, there is a flare-up of clinical signs during the post-patent period and termed post patent parasitic bronchitis [2]. The variation with anthelmintic usage was clearly indicating as the non-dewormed sheep with higher infection prevalence than dewormed counter parts. When the infection prevalence on anthelmintic usage base was subjected to analysis, the difference is statistically significant $(\mathrm{P}<0.05)$. The observation noted on the dewormed sheep in this study was in agreement with the work of Sefinew (1999). Even though the dewormed sheep revealed low infection prevalence compared to non-dewormed groups, about $7.1 \%$ of them were still infected with lungworm. The reason behind this result probably, is that sheep which have only cough and/or tachypnea are usually in the prepatent stage of the disease or have small adult worm burden and the anthelmintic used for the treatment of these sheep may be only temporarily suppress egg production of the adult worms $[27,37]$. Though the smaller prevalence of the lungworm infection founded by this study, it is still a constraint with seasonal variation in the year in the study area and hence it requires cooperative effort of the concerned body and different stack holders to reduce the problem effectively.

\section{Conclusion And Recommendations}

The prevalence of ovine lungworm infection recorded in this study was relatively smaller. However, associated risk factors such as management systems, body condition scores, respiratory signs and deworming history were found significantly related with the prevalence of ovine lung worm infection in the study area. Extensively managed sheep were found to be more infected with lung worm than those in semi-intensive management system. The highest prevalence was observed in non-dewormed animals than animals of the corresponding group. Despite, lower prevalence of lungworm infection obtained in the present study within the specified study period, it is still a constraint among different season of the year in the area and hence requires strong attention. Therefore, in light of the above conclusion the following recommendations are forwarded:

Vigorous controlling activities like regular strategic deworming (at the end of dry season before the rain starts and after long heavy rainy season) of the whole flock rather than treating individual animals should be performed to decrease the occurrence of disease.

$>$ Extensive extension service should also be launched to make the sheep owners aware of the disease for improvement ofthe economic benefits and productivity of their animals.

$>$ Traditional(extensive) production system in area made to be modernizing for general health care and production advancement. $>$ Due to its impact on production, emphasis should begiven for the control and prevention of lungworminfections.

\section{References}

[1]. Abdella S, Abdela A, Abduselam A, Daniel B, Fikre N, et al., (2016) Prevalence Of Ovine Lungworms In Munesa District, East Arsi, Ethiopia. 8(7): 40-43.

[2]. Abebe M, Shenkute A, Teklu M, Etsay K, Asefa Y, et al., (2014) Prevalence and Identification of Ovine Lungworms in and Around Assela Town, central Ethiopia. American-Eurasian J Sci Res. 9(5): 136-142.

[3]. Addis M, Fromsa A, Ebuy Y (2011) Study on the prevalence of lungworm infection in small ruminants in Gondar town, Ethiopia. J Anim Vet Adv. 4(3): 85-89.

[4]. Aillo S, Mays A (1998) The merck veterinary manual. (8th edn), merck and co, Inc, White house station, NJ- USA. 131-133.

[5]. Alemu S, Gelaye E, Ayele G, Zeleke A (2006) Study on Small Ruminant Lungworm in North-East Ethiopia. J Vet Para. 142(4): 330-335.

[6]. Asaye M, Alemneh T (2015) Prevalence of Lungworm Infection of Small Ruminants in and Around Bahir Dar City, Amhara Regional State, Ethiopia. J Vet Sc Tech. 12: 002.

[7]. Basaznew B, Ayalew E, Achenef M (2012) Ovine Lungworm Infection: Prevalence, Species Composition and Associated Risk Factors in Dessie Zuria District, Northeastern Ethiopia. Afr J Bas Appl Sci. 4(3): 73-76.

[8]. Beyene D, Nigussie S, Ayana D, Abunna F (2013) The prevalence of lungworms in naturally infected sheep of Ambo District, Oromia, Ethiopia. Glob Vet. 10: 93-98.

[9]. Borji H, Azizzadeh M, Ebrahimi M, Asadpour M (2012) Study on small ruminantlungworms and associated risk factors in northeastern Iran. Asian Pac J Trop Med. 5(11): 853-856.

[10]. Bradford P (2002) Animal Internal Medicine: disease of horses, cattle, sheep and goats. (3rd edn.. Mosby Inc. 514-515, 1452-1455.

[11]. COWS (Control of Worms Sustainably) (2014) Control of lungworm in cattle.

[12]. Craig T (1998) Epidemiology of internal parasites: Effect of climate and host reproductive cycles on parasite survival. Proceedings of the Small Ruminants for the Mixed Animal Practitioner, Western Veterinary Conference, Las Vegas. 114-127.

[13]. CSA (Central Statistics Authority) (2010) Agricultural Sample Survey. report on area and production of major crops, statistical bulletin. Addis Ababa: The federal democratic republic of Ethiopia.

[14]. Dar L, Darzi M, Mir M, Kamil S, Rashid A, et al., (2012) Prevalence and Pathology of Lung Worm Infection in Sheep in Kashmir Valley, India. J Anim Sc Adv. 2(8): 678-685.

[15]. Elsheikh H, Khan N (2011) Essentials of Veterinary Parasitology. (1st edn), Caister Academic Press, Norfolk, UK. 52-69.

[16]. ESGPIP (Ethiopia Sheep and Goat Productivity Improvement Program) (2007): Control of Internal Parasites in Sheep and Goats. Technical Bulletin. 3.

[17]. Eyob E, Matios L (2013) The prevalence and risk factors associated with ovine lungworm infestation in the Asella province, Central Ethiopia. J Para Vector Bio. 5(8): 116-121.

[18]. Fentahun T, Yohanes S, Moges C, Nibret M (2012) Prevalence of Lungworm Infection in Small Ruminants in and Around Jimma Town, Southwest Ethiopia. Global Vet. 9(5): 580-585.

[19]. Hasen A, Takele S, Simenew K (2013) Ovine lungworm infection rate on fecal larvae recovery basis. J Acta Para Glob. 4(1): 29-33.

[20]. Ibrahim N, Godefa Y (2012) Prevalence of Ovine Lung Worm Infection in Mekelle Town, North Ethiopia. Int J Vet Med. 9(1): 1-15.

[21]. ILRI (International Livestock Research Institute) (2000) Hand book of livestock statistical for developing countries socio-economic and policy research working paper Nairobi, Kenya. 299.

[22]. Kebede S, Menkir S, Desta M (2014) On farm and Abattoir study of Lungworm infection of small ruminants in selected areas of Dale District, Southern Ethiopia. Int J Current Micr App Sc. 3(4): 1139-1152.

[23]. Kimberling CV (1988) Disease of sheep. (3rd edn), Leaftbiger, Philadelphia. 99.

[24]. Mesfin N (2008) Study on prevalence of Small ruminant lungworm in and 
around Kombolcha, South Wollo, Ethiopia. In DVM Thesis, FVM, Haramaya Univesity, Haramaya, Ethiopia. 38-43.

[25]. Mihreteab B, Aman A (2011) Ovine Lungworms in Tiyo District, SouthEast Ethiopia: Prevalence, Effect of Altitude and Major Host Related Risk Factors. Global Vet. 7(3): 219-225.

[26]. Moges N, Bogale B, Chanie M (2011) Dictyocaulus Filaria and Muellerius capillaris are Important Lungworm Parasites of Sheep in Wogera District, Northern Ethiopia. Int J Anim Vet Adv. 3: 465-468.

[27]. Radostitis O, Gay C, Chliff K, Constable P (2007) A text book of diseases of cattle, horses, sheep, pigs and goats. (10 th edn), St. Louis, Philadelphia, London. 1568- 1569.

[28]. Regassa A, Toyeb R, Abebe B, Megersa B, Mekibib S, et al., (2010) Lungworm infection in small ruminants: Prevaence and associated risk factors in Dessie and Kombolcha districts, northeastern Ethiopia. Vet Para. 169(2): 144-148.

[29]. Sefinew A (1999) Survey of small ruminant lungworm in six district of Wollo, DVM thesis, Faculty of Veterinary Medicine, Addis Ababa University Debreziet. 69.

[30]. Selam T, Yohannes H, Awot T, Getachew G, Berihu G (2015) Ovine Lung Worm Infection and Associated Risk Factors in and Around Wukro, Eastern Tigray, Ethiopia. Euro J Bio Sc. 7(3): 120-124.

[31]. Soulsby E (1982) Helminths, Arthropods and Protozoa of Domesticated Animals, Seventh Edition. Bailliere Tindall, London: Lea and Febiger, Philadelphia. 212-258.
[32]. Tefera, mekuria (2016) Lungworm Infection in Ovine: Prevalence and Associated Risk Factors in Debre Birhan Town Ethiopia. J Vet Sc Tech. 7(303): 2157-7579.

[33]. Terefe Y, Tafess K, Fekadie G, Kebede N (2013) Prevalence of lungworm infection in small ruminants in North Gondar zone, Amhara National Regional State, Ethiopia. J Para Vector Biol. 5: 40-45.

[34]. Tewodros A (2015) A Review on: Lungworm Infection in Small Ruminants. J World Pha Life Sc. 1(3): 149-159.

[35]. Thomson E, Orita G (2008) Seasonal prevalence of Protostrongylid and Dictyocaulus species of Lung worms in Awassi Sheep in North-west Syria. J Trop Ani Heal Prod. 20: 187-189.

[36]. Thrusfield M (2007) Veterinary epidemiology. (3rd edn), BlackWell Science Ltd. Cambridge, USA. 225-228.

[37]. Urquhart G, Armour J, Duncan A, Jennings F (1996) Veterinary Parasitology. 2nd edn. Blackwell Science, Scotland. 39-58.

[38]. Weldesenebet D, Mohamed A (2012) Prevalence of small ruminant lung worm infection in Jimma town. Glob Vet. 8(2): 153-159.

[39]. Yifat D, Adugnaw M, Rahmeto A, Desie S (2013) Prevalence of Lungworm Infection in Sheep around Bahir-Dar Town, Northern Ethiopia. Acta Parasitologica Globalis. 4 (2): 54-58.

[40]. Yimer A, Desie A (2016) Epidemiological Studies on Ovine Lungworm Species in Northern Ethiopia. J Vet Sci \& Tech. 7(6): 2157-7579. 